\title{
Angelman Syndrome in Adulthood
}

\author{
Anna M. Larson ${ }^{1}$, Julianna E. Shinnick ${ }^{1}$, Elias A. Shaaya ${ }^{1}$, Elizabeth A. Thiele ${ }^{1}$, and Ronald \\ L. Thibert ${ }^{1}$ \\ ${ }^{1}$ Pediatric Epilepsy Program, Department of Neurology, Massachusetts General Hospital, Boston, \\ Massachusetts
}

\section{Abstract}

Angelman syndrome (AS) is a neurogenetic disorder. The goal of this study was to investigate the primary health issues affecting adults with AS and to further characterize the natural history and genotype-phenotype correlations. Standardized phone interviews with caregivers for 110 adolescents and adults with AS were conducted. The impact of age, gender, and genotype on specific outcomes in neurology, orthopedics, internal medicine, and psychiatry were investigated. The mean age of individuals with AS was 24 years (range 16-50y). Active seizures were present in $41 \%$ of individuals, and $72 \%$ had sleep dysfunction. Significant constipation was present in $85 \%$, and $32 \%$ were overweight or obese, with obesity disproportionately affecting women. Scoliosis affected $50 \%$ with a mean age at diagnosis of 12 years, and $24 \%$ of those diagnosed with scoliosis required surgery, an intervention disproportionately affecting men. Sixty-eight percent were able to walk independently, and $13 \%$ were able to speak 5 or more words. Self-injurious behavior was exhibited in $52 \%$ of individuals. The results of this study indicate that epilepsy severity may assume a bimodal age distribution: seizures are typically most severe in early childhood but may recur in adulthood. While late-adolescent and adult sleep patterns were improved when compared to the degree of sleep dysfunction present during infancy and childhood, the prevalence of poor sleep in adults remained quite high. Primary areas of clinical management identified include the following: seizures, sleep, aspiration risk, GERD, constipation, dental care, vision, obesity, scoliosis, bone density, mobility, communication, behavior, and anxiety.

\section{Keywords}

Angelman syndrome; adults; seizures; behavior; self-injury

\section{INTRODUCTION}

Angelman syndrome (AS) is a neurogenetic disorder clinically characterized by features of epilepsy, poor sleep, ataxia, frequent smiling/sociability, and scoliosis. Individuals typically have severe cognitive impairment and limited expressive speech. Eighty to $90 \%$ of individuals with AS develop seizures, which may include multiple semiologies [Thibert et al., 2009]. Children may have gross motor delays, sitting at an average age of 20.5 months

Corresponding Author: Ronald L. Thibert, DO, MsPH, Pediatric Epilepsy Program, Massachusetts General Hospital, 175 Cambridge Street, Suite 340, Boston, MA 02114, Phone: 617.726.0241, Fax: 617.726.0230, rthibert@ partners.org. 
and walking at 3.7 years, and $10 \%$ of individuals with AS do not develop the ability to walk independently [Williams et al., 2010]. Although many children with AS have significant receptive language skills, the majority of individuals gain very few words [Jolleff et al., 1993, Williams 2005].

AS has an estimated incidence of approximately 1 in 12,000-20,000 live births, but life expectancy by epidemiologic measures remains unknown [Williams et al., 2010]. The molecular etiology of AS is a loss of function of the maternally inherited UBE3A gene, which codes for E6AP-3A ubiquitin protein ligase [Knoll et al., 1989, Albrecht et al., 1997, Kishino et al., 1997]. There are 4 molecular subtypes of AS, and deletion of the 15q11.213.1 region (Del) is the most common. Mutation of the maternal $U B E 3 A$ gene, paternal uniparental disomy (UPD), and imprinting defects also cause an AS phenotype [Knoll et al., 1989, Malcom et al., 1991, Buriting et al., 1995, Kishino et al., 1997, Matsuura et al., 1997].

The first individuals to undergo genetic testing for AS in early childhood during the late 1980s are now young adults. Over the past 3 decades, there has been significant progress in diagnostics and care for adults with AS. Drs. Jill Clayton-Smith and Charles Williams were the pioneers of this field and among the first to characterize the adult phenotype and to study the impact of age [Williams et al., 1982, Clayton-Smith et al., 1993]. In 1984, Bjerre et al. contributed a case report of a 75-year-old patient with a clinical diagnosis of AS from Sweden who was described to be in generally good health [Bjerre et al., 1984]. The case, which features the oldest patient reported in the literature, played a pivotal role in AS research, as it provided some evidence that the disease was not a degenerative process [Bjerre et al., 1984, Sandanam et al., 1997]. Today, research on aging in the setting of AS continues to advance, and quality of life for the majority of individuals with AS has been found to be maintained into adulthood [Bjerre et al., 1984, Clayton-Smith et al., 2003]. In this study, investigators aimed to further characterize the natural history and current clinical manifestations of AS in adulthood.

\section{MATERIALS AND METHODS}

This institutional review board-approved study conducted at the Massachusetts General Hospital investigated AS in adulthood with subject data collected by a series of phone interviews with primary caregivers. Subject recruitment information was sent by e-mail to close to 1,120 addresses from the Angelman Syndrome Foundation (ASF) database. Study information was also posted to the "Current Research" page on the ASF website. Subject inclusion criteria were as follows: diagnosis of AS by a physician, 16 years of age or older, interviewee self-identification as one of the subject's primary caregivers. Subjects were from 34 states in the United States, Puerto Rico, and 2 Canadian provinces. All interviews were completed over a period of 4 months in 2011. The impact of age, gender, and genotype on specific outcomes in neurology, internal medicine, orthopedics, and psychiatry were investigated. The interview consisted of a set of standardized questions developed by the investigators. In addition, there were several designated points in the interview during which participants were asked to describe additional pertinent medical history not specifically covered in the standardized questions. The investigators were contacted by 3 families with a son or daughter with AS who had previously died. These caregivers completed the 
standardized interview, and their responses were included in the full data set. In one case, the subject had died prior to an AS diagnosis; however, his sibling, who had a similar phenotype, was subsequently diagnosed with AS, identified by a mutation in $U B E 3 A$. Both siblings were therefore included and reported as having the same associated genotype. One subject had a diagnosis of mosaicism (unknown to investigators if the individual's genotype was an imprinting defect or a chromosomal type). Because she was a genotypic outlier, her case data were not included in the full cohort analyses.

The interview included a modified Early Childhood Epilepsy Severity Scale (E-Chess) [Humphrey et al., 2008]. The score was modified from the rubric initially described by Humphrey et al. in two ways: (a) "time period over which seizure occurred" was eliminated, given that the full cohort would receive the same score ("more than 6 months"); (b) "response to treatment" was reduced to 1 of 2 possible responses, "complete cessation" or "partial/no improvement" [Humphrey et al., 2008]. Caregivers were asked the age range during which seizures were most severe, and the median age was calculated. Episodes reported by caregivers as seizures were recorded as such; however, in many cases, the patients had not recently undergone electroencephalography (EEG).

Categorical data were presented as frequencies and compared using a 2-sided Fisher exact test. Continuous data were presented as mean \pm standard deviation (SD). Covariate impact was measured by linear regression for continuous variables and logistic regression for nominal or ordinal variables. Multivariate regression analyses assessing gender and age included the full cohort $(\mathrm{n}=109)$. Univariate regression analyses assessing genetic impact included the cohort of individuals with a known genotype (Del, $U B E 3 A$, UPD) (n=93). Alpha was set at 0.05 .

\section{RESULTS}

Cohort demographic data are presented in Table I. There were no statistically significant differences in age or gender between the known genotype ( $n=93$ ) cohort and the subset of individuals with a clinical diagnosis or unknown genotype $(\mathrm{n}=16)$. Epilepsy and sleep data are reported in Tables II and III. There was no association between having active seizures and sleep problems $(\mathrm{p}=0.506)$ and/or co-sleeping $(\mathrm{p}=0.423)$. Five cases were reported to have prolonged episodes of rhythmic shaking of their arms, legs, face, or whole body (F22, F24, M24, M29, M49). Events occurred only when the individuals were awake, and maximum duration ranged from 1 to 6 hours. Event frequency ranged from 3 events per year to 2 events per day prior to treatment. Triggers included menstruation, systemic illness, constipation, exhaustion, stress, and anger.

Table IV presents internal medicine data. In the treatment of gastroesophageal reflux disease (GERD), 6 individuals underwent Nissen fundoplication: 4 had the procedure before the age of 2 years (F18, M21, M24, M32), and 2 had the procedure in their twenties (F24, M20). Four individuals had a history of gastroparesis (F21, F26, M17, M24). From an ophthalmologic perspective, F32 had extreme sensitivity to bright sun in her eyes; M26 developed keratoconus from persistent eye rubbing behavior; M32 was legally blind; and M24 had been diagnosed with cortical visual impairment. Tables V and VI present 
anthropomorphic, orthopedic, mobility, and exercise data. Mean female height was 1.55 meters (sd: 0.084), and male height was 1.68 meters (sd: 0.099). Scoliosis was not associated with the independently mobile $(\mathrm{p}=0.816)$ or non-ambulatory $(\mathrm{p}=0.242)$ covariates.

Table VII presents data on communication and activities of daily living. Recurrent themes included the following: significant receptive language skills; typically able to communicate needs and wants using direct objects; highly sensitive to voice tone, specifically when aggressive or confrontational; a demonstrated ability to make meaningful connections with people, despite limited expressive language. Table VIII presents data on challenging behaviors in AS. The most commonly cited challenging behaviors were as follows: pulling others' hair (31\%), hitting others (28\%), yelling/screaming (21\%), pulling on others (19\%), dropping to the floor (18\%), hugging too tightly and/or hugging strangers (17\%), biting others (17\%), chewing clothing (16\%), chewing plastic (13\%), pinching others (13\%), hitting self (12\%), biting nails (12\%), kicking others (11\%), banging head (10\%). The majority of the AS cohort had never been evaluated by a psychiatrist; however, $46 \%$ ( $n=48)$ of caregivers felt that the individual had shown some signs of anxiety. Alternatively, only $2 \%$ of caregivers endorsed possible signs of depression.

M16 died in a drowning accident in the home. F24 died of pneumonia in the setting of severe seizures, and M38 died of metastatic lung cancer. Of the interviewed caregivers, 55\% endorsed having back pain or other chronic pain symptoms. Thirty-seven percent endorsed feelings of isolation, and 19\% were unable to identify a source of emotional support. Caregivers endorsed significant anxiety about the future: $30 \%$ described the anxiety as moderate, and $18 \%$ described it as severe.

\section{DISCUSSION}

The results of this study were limited by the interview design, which did not include a physical exam by a physician or medical record review. Given that participants were recruited through the ASF, this study may have a response bias toward a more severe medical phenotype. Additionally, a larger proportion of the study cohort was living with parents (75\%) compared to a clinical series of adults with AS (ages 16 to 40 years) reported by Clayton-Smith et al., in which about half the study cohort continued to live with parents [Clayton-Smith et al., 2001]. The study cohort provided a relatively close representation of the genotypic distribution seen in the general AS population, with the exception of a mildly increased UPD subset and an absence of any subjects with an imprinting defect: Del 6575\% (study 68\%), UBE3A 5-11\% (8\%), imprinting defect 3\% (0\%), UPD 3-7\% (9\%) [Williams et al., 2010].

\section{Neurology}

Epilepsy is one of the primary health concerns for adults with AS and is the leading cause of hospitalization across age groups [Thomson et al., 2006]. The literature suggests that the period of greatest epilepsy severity is typically early childhood and that seizures often improve over the first decade and a half of life [Matsumoto et al., 1992, Clayton-Smith et al., 1993, Smith et al., 1996, Viani et al., 1995, Valente et al., 2006, Thibert et al., 2009, Pelc et 
al., 2008, Uemura et al., 2005]. According to the literature, individuals with AS may then experience a quiet period or seizure remission through their late teens and early twenties, followed by a possible recurrence of seizure severity during their third and fourth decades [Clayton-Smith et al., 1993, Thibert et al., 2009, Laan et al., 1996, Laan et al., 1997, Clayton-Smith et al., 2001, Williams et al., 1982, Matsumoto et al., 1992, Moncla et al., 1999, Thomson et al., 2006, Buckley et al., 1998]. Consistent with prior series, the vast majority of this study cohort (94\%) had a history of seizures [Thomson et al., 2006, Smith et al., 1996, Laan et al., 1997], and the majority of adults (77\%) experienced their most severe seizures before age 11 . We found a similarly bimodal distribution of seizure severity, with decreased rates of seizure-freedom and increased seizure severity scores, for individuals over 25 years compared to those 16 to 20 years of age.

Previously, across age groups, the Del genotype has been found to confer the most severe epilepsy phenotype, followed by UBE3A. The UPD population has been found to exhibit the least severe epilepsy phenotype [Minassian et al., 1998, Clayton-Smith et al., 2003, Lossie et al., 2001, Moncla et al., 1999]. In our study we found that individuals with $U B E 3 A$ had significantly decreased odds of developing seizures under the age of 3 compared to the Del cohort, and no one with this genotype had more than one seizure semiology. The UPD cohort had significantly decreased odds of developing epilepsy compared to the Del cohort, and no one with this genotype experienced daily seizures.

With an EEG correlate, sustained shaking episodes without loss of consciousness have been described in individuals with AS as myoclonic status in non-progressive encephalopathy (MSNE) [Pelc et al., 2008, Dalla Bernardina et al., 1985, Elia et al., 2009, Valente et al., 2006, Guerrini et al., 1996, Ogawa et al., 1996, Dalla Bernardina et al., 1995, Viani et al., 1995]. Without an EEG correlate, similar episodes of sustained shaking have also been clinically identified in AS and have been described as cortical myoclonus [Guerrini et al., 1996, Stecker et al., 2003, Pelc et al., 2008, Guerrini et al., 2003]. Based on clinical experience with other adult AS patients, the investigators hypothesize that the shaking episodes described by the caregivers in this study are likely consistent with cortical myoclonus; follow-up studies that incorporate electrophysiological data are being conducted to further characterize this pathology in the adult AS population.

AS may also confer significant sleep problems [Walz et al., 2005, Conant et al., 2009]. The pathophysiologic mechanism of epilepsy and sleep dysfunction in AS may be secondary to haploinsufficiency and decreased expression of a GABA receptor gene, specifically GABRB3 on 15qll-13, adjacent to UBE3A [Minassian et al., 1998, Lossie et al., 2001, DeLorey et al., 1996, Nolt et al., 2003]. While significant sleep problems during infancy and early childhood are nearly universal among individuals with AS, it has been previously reported that sleep dysfunction may improve with age [Smith et al., 1996, Miano et al., 2004, Clayton-Smith et al., 2001, Sandanam et al., 1997]. The results of this study support this hypothesis: the majority of caregivers described current sleep patterns as improved when compared to the degree of sleep dysfunction experienced during infancy and childhood. The prevalence of poor sleep in adults, however, remained quite high, affecting the majority (72\%) of the cohort. 
Our results indicate sleep dysfunction in multiple domains for adults with AS, including increased sleep latency, night waking, and daytime sleepiness. Consistent with prior rates of increased sleep latency (48-50.5\%) across age groups [Walz et al., 2005, Conant et al., 2009], $65 \%$ of this study's cohort had trouble falling asleep. Sandanam et al. found that $54 \%$ of adults (Del) had significant nighttime waking, and, similarly, 66\% percent of this cohort was reported to have difficulty staying asleep [Sandanam et al., 1997]. Prior studies have shown a decreased need for sleep in children with AS [Conant et al., 2009, Clayton-Smith et al., 1993]. However, our results indicate a reported average of 7.4 hours of sleep per night and some evidence of daytime sleepiness. These findings suggest that adults may not show the same degree of decreased need for sleep as younger individuals [Clayton-Smith et al., 1993]. The interaction between epilepsy and sleep dysfunction is not well understood, but these pathologies often coexist in the general epilepsy population, as well as in the AS population [Conant et al., 2009]. In this study, however, ongoing seizure activity was not significantly associated with sleep problems.

\section{Internal medicine}

The pathophysiologic impact of AS on the pulmonary, endocrine, and gastrointestinal systems has not been formally investigated in the adult population. We report high rates of pneumonia, choking episodes with eating, and resistant behavior surrounding drinking fluids. Very few individuals had undergone a formal speech and swallow study in the past, but our findings suggest that many adults with AS may have some degree of orapharyngeal dysfunction. Episodic gagging unrelated to eating was also common and for some, these gagging episodes had an olfactory trigger or anxiety component. These episodes appear quite uniform across the study population and may represent a form of stereotypy. Further, although AS is not traditionally associated with true hyperphagia, as is common in PraderWilli syndrome [Clayton-Smith et al., 2001], we found that half the individuals were reported to not self-regulate food intake and/or to exhibit a (suspected) limited sense of fullness. Caregiveres of females more often reported limited satiety.

Gastrointestinal health issues, specifically gastroesophageal reflux disease (GERD) and constipation, are common among adults with AS and often require ongoing medical management [Clayton-Smith et al., 2001]. Previously, Clayton-Smith et al. reported potentially severe reflux in adulthood, including a case of stricture requiring surgical intervention [Clayton-Smith et al., 2001]. Similarly, a substantial proportion of our cohort with GERD did not improve with medical treatment, and 2 individuals underwent Nissen fundoplication in adulthood. Constipation was nearly universal, often requiring medical management. These results show that diagnostics in internal medicine often pose a significant clinical challenge, and common pathologies of the alimentary tract can be severe and may require long-term medical management.

\section{Ophthalmology}

The prevalence and natural history of visual impairment in AS remains unclear. In the AS adult literature, there have been several reports of keratoconus, typically developing secondary to recurrent eye rubbing behaviors as was described in this study [Laan et al., 1996, Williams et al., 1982, Bjerre et al., 1984, Clayton-Smith et al., 2003, Sandanam et al., 
1997]. In an adult series, strabismus and/or a pale fundus were the primary issues identified on ophthalmologic exam [Buntinx et al., 1995]. In a second report, retinochoroidal atrophy (RCA) with optic disk paleness was described in 2 adult patients, and Rufa et al. hypothesized that the RCA may be secondary to impaired ubiquitination and subsequent retinal photooxidative damage with age [Rufa et al., 2003].

\section{Anthropometrics}

Obesity is a major health concern for adults with AS [Van Buggenhout et al., 2009, Laan et al., 1996, Clayton-Smith et al., 2001, Smith et al., 1996, Thomson et al., 2006]. Thirty-two percent of the adults in this study were overweight or obese. We found that women in the cohort had increased odds of developing obesity, consistent with a prior report [ClaytonSmith et al., 2001]. Alternatively, Smith et al. observed obesity disproportionately affecting men [Smith et al., 1996]. Genotypic differences in the rates of obesity have been reported, with Del cohorts showing lower BMIs compared to non-deletion [Moncla et al., 1999]. In this study, however, no statistically significant genotype-phenotype correlations were observed. Weight management in the AS population is a complex issue potentially involving multiple factors, including genetic predisposition, aberrant sense of satiety, limited access to opportunities for exercise, and challenging behaviors related to food.

\section{Orthopedics}

Many adults with AS have had previous orthopedic care. Thoracic scoliosis affects about $10 \%$ of children with AS, but with age, scoliosis becomes more pervasive [Clayton-Smith et al., 2001, Clayton-Smith et al., 2003]. Prior reported prevalence rates of scoliosis span a broad range in adult AS cohorts (38.8\%-71\%) [Buntinx et al., 1995, Laan et al., 1996, Thomson et al., 2006], but in this study half the individuals had scoliosis. Clayton-Smith et al. observed that scoliosis progressed faster in non-ambulatory patients [Clayton-Smith et al., 1993], but Laan et al. alternatively hypothesized that this may not be causative, given that scoliosis can be identified in both ambulatory and non-ambulatory individuals [Laan et al., 1996]. In this study, no association was found between scoliosis and mobility parameters, but further prospective investigation is indicated. Laan et al. reported a significant difference in the rates of scoliosis by sex, with $92 \%$ of females and $56 \%$ of males affected [Laan et al., 1996]. Clayton-Smith et al. described a similar female predominance [Clayton-Smith et al., 2003]. Conversely, in this study, statistically significant differences in rates of scoliosis by sex, age, or genotype were not observed, but males did have increased odds of undergoing surgical intervention. Coppola et al. suggested that given the combination of limited mobility and chronic AED treatments, individuals with AS may have increased risk of fractures due to decreased bone density [Coppola et al., 2007]. We found that the individuals in their early twenties had increased odds of being diagnosed with osetopenia/osteporosis. This result is confounded by the fact that this age group may be more likely to have undergone bone density screening compared to the 16- to 20-year-old cohort. Based on these findings, primary orthopedic issues for adults with AS include scoliosis, contractures, and fractures. 


\section{Mobility}

In the AS population, there is a complex interplay between independent mobility and many distinct parameters, including ataxia and gross motor development, obesity, scoliosis, hypertonia, bone density, and voluntary behavior [Clayton-Smith et al., 2001, Clayton-Smith et al., 2003, Van Buggenhout et al., 2000, Van Buggenhout et al., 2009]. We found that the majority of our cohort was able to walk independently (68\%), consistent with the rate previously reported for an adult cohort (75\%) [Clayton-Smith et al., 2001]. From a genetic perspective, adults with $U B E 3 A$ and UPD, compared to those with a Del, have been found to have increased mobility [Moncla et al., 1999, Clayton-Smith et al., 2001]. In this study, however, only the UPD cohort had a statistically significant increase in mobility. Further, we found that adults with AS showed a capacity to learn to swim independently and participate in a wide range of physical activities including riding an adaptive bike, hippotherapy, and yoga. Consistent access to opportunities for routine exercise, however, remains a significant challenge.

\section{Communication}

Severe oral motor dyspraxia with absent or limited expressive speech is nearly universal in AS across age groups, with a significant discrepancy between expressive and receptive language abilities [Clayton-Smith et al., 1993, Penner et al., 1993, Didden et al., 2009, Laan et al., 1996, Moncla et al., 1999, Jolleff et al., 1993]. Individuals with AS communicate through multiple modalities, including vocalizations, signs or gestures, pictures, and electronic devices [Clayton-Smith et al., 1993, Calculator et al., 2013]. Previously, ClaytonSmith et al. found that $68 \%$ of adults with AS were able to communicate their basic needs, primarily through the use of gestures [Clayton-Smith et al., 2001]. In this study, a minority of individuals (13\%) had facility with 5 or more words. Individuals showed use of multiple communication modalities, with the use of signs or gestures (including reaching/pointing) and the use of sounds with meaning, the two most common. The speech-language phenotype for $U B E 3 A$ and UPD is typically less severe [Lossie et al., 2001, Clayton-Smith et al., 2001, Clayton-Smith et al., 2003, Moncla et al., 1999]. In this study, individuals with $U B E 3 A$ had increased odds of developing some speech, and both non-deletion sub-groups had increased odds of using signs or natural gestures. Didden et al. similarly found increased use of signs and gestures among individuals with UPD compared to Del [Didden et al., 2009]. Finally, music was nearly universally (90\%) described as very important and independently motivating for our cohort.

\section{Challenging behavior}

Aggressive and self-injurious behavior can lead to significant morbidity. Every day, challenging behaviors directly impact opportunities for community involvement and social inclusion, which can lead to increased isolation, often perpetuating behavior problems. Importantly, aggressive behaviors in AS (behaviors with the potential of harming others) are often without malicious intent, but rather with goals of social engagement. Prior studies have reported the prevalence of aggressive behavior at much lower rates (6-10\%) in individuals across age groups in comparison to our cohort (72\%) [Summers et al., 1995, Adams et al., 2011]. Contributing to this difference may be variable definitions of aggression and the size 
and strength of adults, as some behaviors considered benign in childhood may become more problematic when expressed in adulthood.

In a prior study of communication in AS, Didden et al. indicated that aggressive behaviors were often used as a communication method for rejection/protest, suggesting a negative reinforcement maintenance mechanism [Mudford et al., 2008, Didden et al., 2009]. Laan et al. described sensory stimulation behavior in adults with AS, with chewing/mouthing behavior affecting $75 \%$ of the study cohort [Laan et al., 1996]. Consistent with these reports, our data similarly suggests that behaviors in AS typically serve multiple functions, including seeking social attention, communicating tangible demand/avoidant escape, and seeking sensory stimulation. Clinically, acute changes in behavior require thorough evaluation for a possible as-yet unrecognized illness or injury.

Anxiety is likely under-recognized in this population and may also contribute to challenging behavior [Clayton-Smith et al., 2001]. The therapeutic impact of medical management of anxiety on self-injurious and/or aggressive behaviors in AS is largely unknown, but our data suggest a decrease in the use of antipsychotic and stimulant/antihypnotic medications, stable use of SSRIs, and an increase in the use of anxiolytics. From an environmental perspective, Clayton-Smith et al. previously described adults with AS as often quite sensitive to changes in routine, a trend also seen in this study [Clayton-Smith et al., 2001].

\section{Conclusions}

As part of the longitudinal clinical care of adults with AS, primary areas of clinical management include the following: seizures, sleep, aspiration risk, GERD, constipation, dental care, vision, obesity, scoliosis, bone density, mobility, communication, behavior, and anxiety. Given the results of this study, adults with AS may require lifelong epilepsy management, as seizures have the potential to recur and/or progress in severity with age in a subset of the population, though they tend to improve with age. Additionally, sleep dysfunction, though it often improves over an individual's lifetime, continues to impact the majority of adults and may require behavioral and/or pharmacological intervention. The multiple domains of healthcare in AS are best served by a comprehensive approach and an interdisciplinary team, working towards the goals of health and wellness, safety, social inclusion, and autonomy.

The results of this study demonstrate a profound need for improved understanding of the natural history of seizures in AS and ongoing inquiry into innovative treatment options for epilepsy and other neurobehavioral issues in AS. Additional areas of future research include prospective and polysomnographic trials to better characterize sleep and the impact of age in AS. Our findings indicate a need for further research characterizing AS-associated ophthalmologic pathology and also suggest a great need for ongoing innovative research and the development of evidence-based weight management and fitness programs for individuals with AS. Finally, in the area of communication, future investigation of the neurocognitive processing of music in AS may be pursued to further characterize language development and to potentially yield improved adaptive communication technologies. 


\section{Acknowledgments}

Our deepest thanks go to the families who participated in this study for their patience, their overwhelming generosity of their time, and their willingness to share information with investigators. Our thanks also go to the Angelman Syndrome Foundation for their help with subject recruitment. Thank you to Dr. Jane Summers, Eileen Braun, and Renee Pritzker for help with interview development. This study was supported by the Fred and Renee Pritzker Family. Many thanks to Dr. Hang Lee for his support and guidance with statistical analyses and manuscript review. This work was conducted with support from Harvard Catalyst | The Harvard Clinical and Translational Science Center (NIH Award \#UL1 RR 025758 and financial contributions from Harvard University and its affiliated academic health care centers). The content is solely the responsibility of the authors and does not necessarily represent the official views of Harvard Catalyst, Harvard University, and its affiliated academic health care centers, the National Center for Research Resources, or the National Institutes of Health.

\section{References}

Adams D, Horsler K, Oliver C. Age related change in social behavior in children with Angelman syndrome. Am J Med Genet A. 2011; 155:1290-1297.

Albrecht U, Sutcliffe JS, Cattanach BM, Beechey CV, Armstrong D, Eichele G, Beaudet AL. Imprinted expression of the murine Angelman syndrome gene, Ube3a, in hippocampal and Purkinje neurons. Nat Genet. 1997; 17:75-78. [PubMed: 9288101]

Bjerre I, Fagher B, Ryding E, Rosén I. The Angelman or "happy puppet" syndrome. Clinical and electroencephalographic features and cerebral blood flow. Acta Paediatr Scand. 1984; 73:398-402. [PubMed: 6741540]

Buckley RH1, Dinno N, Weber P. Angelman syndrome: are the estimates too low? Am J Med Genet. 1998; 80:385-390. [PubMed: 9856568]

Buiting K, Saitoh S, Gross S, Dittrich B, Schwartz S, Nicholls RD, Horsthemke B. Inherited microdeletions in the Angelman and Prader-Willi syndromes define an imprinting centre on human chromosome 15. Nat Genet. 1995; 9:395-400. [PubMed: 7795645]

Buntinx IM, Hennekam RCM, Brouwer OF, Stroink H, Beuten J, Mangelschots K, Fryns JP. Clinical profile of Angelman syndrome at different ages. Am J Med Genet. 1995; 56:176-183. [PubMed: 7625442]

Calculator SN. Use and acceptance of AAC systems by children with Angelman syndrome. J Appl Res Intellect Disabil. 2013; 26:557-567. [PubMed: 23606637]

Clayton-Smith J. Clinical research on Angelman syndrome in the United Kingdom: observations of 82 affected individuals. Am J Med Genet. 1993; 46:12-15. [PubMed: 7684188]

Clayton-Smith J. Angelman syndrome: evolution of the phenotype in adolescents and adults. Dev Med Child Neurol. 2001; 43:476-480. [PubMed: 11463179]

Clayton-Smith J, Laan L. Angelman syndrome: a review of the clinical and genetic aspects. J Med Genet. 2003; 40:87-95. [PubMed: 12566516]

Conant KD, Thibert RL, Thiele EA. Epilepsy and the sleep-wake patterns found in Angelman syndrome. Epilepsia. 2009; 50:2497-2500. [PubMed: 19453716]

Coppola G, Verrotti A, Mainolfi C, Auricchio G, Fortunato D, Operto FF, Pascotto A. Bone mineral density in angelman syndrome. Pediatr Neurol. 2007; 37:411-416. [PubMed: 18021922]

Dalla Bernardina B, Fontana E, Zullini E, La Selva L, Franco A, Darra F. Angelman syndrome: electroclinical features of 10 personal cases. Gaslini. 1995; 27:75-78.

Dalla Bernardina, B., Trevisan, E., Colamaria, V., Magaudda, A. Myoclonic epilepsy ('myoclonic status') in non-progressive encephalopathies. In: Roger, J.Dravet, C.Bureau, M.Dreifuss, FE., Wolf, P., editors. Epileptic Syndromes in Infancy, Childhood and Adolescence. London and Paris: John Libbey; 1985. p. 68-72.

DeLorey TM, Minassian B, Datt A, Delgado-Escueta AV, Olsen RW. GABA $\mathrm{A}$ receptor expression is reduced in Angelman syndrome. Society For Neuroscience Abstract. 1996; 22:1166.

Didden R, Sigafoos J, Korzilius H, Baas A, Lancioni GE, O’Reilly MF, Curfs LMG. Form and function of communicative behaviours in individuals with Angelman syndrome. J Appl Res Intellect Disabil. 2009; 22:526-537.

Elia M. Myoclonic status in nonprogressive envephalopathies: an update. Epilepsia. 2009; 50:41-44. 
Guerrini R, Carrozzo R, Rinaldi R, Bonanni P. Angelman syndrome: etiology, clinical features, diagnosis, and management of symptoms. Paediatr Drugs. 2003; 5:647-661. [PubMed: 14510623]

Guerrini R, De Lorey TM, Bonanni P, Moncla A, Dravet C, Suisse G, Livet MO, Bureau M, Malzac P, Genton P, Thomas P, Sartucci F, Simi P, Serratosa JM. Cortical myoclonus in Angelman syndrome. Ann Neurol. 1996; 40:39-48. [PubMed: 8687190]

Humphrey A, Ploubidis GB, Yates JR, Steinberg T, Bolton PF. The early childhood epilepsy severity scale (E-Chess). Epilepsy Res. 2008; 79:139-145. [PubMed: 18387786]

Jolleff N, Ryan MM. Communication development in Angelman syndrome. Arch Dis Child. 1993; 69:148-150. [PubMed: 8024300]

Kishino T, Lalande M, Wagstaff J. UBE3A/E6-AP mutations cause Angelman syndrome. Nat Genet. 1997; 15:70-73. [PubMed: 8988171]

Knoll JHM, Nicholls RD, Magenis RE, Graham JM Jr, Lalande M, Latt SA. Angelman and PraderWilli syndromes share a common chromosome 15 deletion but differ in parental origin of the deletion. Am J Med Genet. 1989; 32:285-290. [PubMed: 2564739]

Laan LA, Renier WO, Arts WF, Buntinx IM, vd Burgt IJ, Stroink H, Beuten J, Zwinderman KH, van Dijk JG, Brouwer OF. Evolution of epilepsy and EEG findings in Angelman syndrome. Epilepsia. 1997; 38:195-199. [PubMed: 9048672]

Laan LA, Th den Boer A, Hennekam R, Renier WO, Brouwer OF. Angelman syndrome in adulthood. Am J Med Genet. 1996; 66:356-360. [PubMed: 9072912]

Lossie AC, Whitney MM, Amidon D, Dong HJ, Chen P, Theriaque D, Hutson A, Nicholls RD, Zori RT, Williams CA, Driscoll DJ. Distinct phenotypes distinguish the molecular classes of Angelman syndrome. J Med Genet. 2001; 38:831-845.

Malcolm S, Clayton-Smith J, Nichols M, Robb S, Webb T, Armour JAL, Jeffreys AJ, Pembrey ME. Uniparental disomy in Angelman syndrome. Lancet. 1991; 337:694-697. [PubMed: 1672177]

Matsumoto A, Toshiyuki K, Kiyokuni M, Miyazaki S, Hayakawa C, Yamanaka T. Epilepsy in Angelman syndrome associated with chromosome 15q deletion. Epilepsia. 1992; 6:1083-1090.

Matsuura T, Sutcliffe JS, Fang P, Galjaard RJ, Jiang YH, Benton CS, Rommens JM, Beaudet AL. De novo truncating mutations in E6-AP ubiquitin-protein ligase gene (UBE3A) in Angelman syndrome. Nat Genet. 1997; 15:74-77. [PubMed: 8988172]

Miano S, Bruni O, Leuzzi V, Elia M, Verrillo E, Ferri R. Sleep polygraphy in Angelman syndrome. Clin Neurophysiol. 2004; 115:938-945. [PubMed: 15003776]

Minassian BA, Delorey TM, Olsen RW, Philippart M, Bronstein Y, Zhang Q, Guerrini R, van Ness P, Livet MO, Delgado-Escueta AV. Angelman syndrome: correlations between epilepsy phenotypes and genotypes. Ann Neurol. 1998; 43:485-493. [PubMed: 9546330]

Moncla A, Malzac P, Voelckel MA, Auquier P, Girardot L, Mattei MG, Philip N, Mattei JF, Lalande M, Livet MO. Phenotype-genotype correlation in 20 deletion and 20 non-deletion Angelman syndrome patients. Eur J Med Genet. 1999; 7:131-139.

Mudford, O., Arnold-Saritepe, A., Phillips, K., Locke, J., Ho, I., Taylor, S. Challenging behavior. In: Matson, J., editor. Clinical Assessment and Intervention for Autism Spectrum Disorders, 1e. New York: Academic Press; 2008. p. 267-297.

Nolt DH, Mott JM, Lopez WL. Assessment of anticonvulsant effectiveness and safety in patients with Angelman's syndrome using an Internet questionnaire. Am J Health Syst Pharm. 2003; 60:25832587. [PubMed: 14735775]

Ogawa K, Ohtsuka Y, Kobayashi K, Asano T, Oka E. The characteristics of epilepsy with Angelman syndrome. Epilepsia. 1996; 37:83-84.

Pelc K, Boyd SG, Cheron G, Dan B. Epilepsy in Angelman syndrome. Seizure. 2008; 17:211-217. [PubMed: 17904873]

Penner KA, Johnston J, Faircloth BH, Irish P, Williams CA. Communication, cognition and social interaction in the Angelman syndrome. Am J Med Genet. 1993; 46:34-39. [PubMed: 8494032]

Rufa A, Dotti MT, Orrico A, Battisti C, Carletto F, Federico A. Retinochoroidal atrophy in two adult patients with Angelman syndrome. Am J Med Genet A. 2003; 122:155-158.

Sandanam T, Beange H, Robson L, Woolnough H, Buchholz T, Smith A. Manifestations in institutionalized adults with Angelman syndrome due to deletion. Am J Med Genet. 1997; 70:415420. [PubMed: 9182785] 
Schneider BB, Maino DM. Angelman syndrome. J Am Optom Assoc. 1993; 64:502-506. [PubMed: 8376719]

Smith AC, Wiles C, Haan E, McGill J, Wallace G, Dixon J, Selby R, Colley A, Marks R, Trent RJ. Clinical features in 27 patients with Angelman syndrome resulting from DNA deletion. J Med Genet. 1996; 33:107-112. [PubMed: 8929945]

Stecker MM, Myers SM. Reserpine responsive myoclonus and hyperpyrexia in a patient with Angelman syndrome. Clin Neurol Neurosurg. 2003; 105:183-187. [PubMed: 12860512]

Summers JA, Allison DB, Lynch PS, Sandler L. Behaviour problems in Angelman syndrome. J Intellect Disabil Res. 1995; 39:97-106. [PubMed: 7787388]

Thibert RL, Conant KD, Braun EK, Bruno P, Said RR, Nespeca MP, Thiele EL. Epilepsy in Angelman syndrome: a questionnaire-based assessment of the natural history and current treatment options. Epilepsia. 2009; 50:2369-2376. [PubMed: 19453717]

Thomson AK, Glasson EJ, Bittles AH. A long-term population-based clinical and morbidity profile of Angelman syndrome in Western Australia: 1953-2003. Disabil Rehabil. 2006; 28:299-305. [PubMed: 16492624]

Uemura N, Matsumoto A, Nakamura M, Watanabe K, Negoro T, Kumagai T, Miura K, Ohki T, Mizuno S, Okumura A, Aso K, Hayakawa F, Kondo Y. Evolution of seizures and electroencephalographical findings in 23 cases of deletion type Angelman syndrome. Brain Dev. 2005; 5:383-388.

Valente KD, Koiffmann CP, Fridman C, Varella M, Kok F, Andrade JQ, Grossmann RM, MarquesDias MJ. Epilepsy in patients with Angelman syndrome caused by deletion of the chromosome 15q11-13. Arch Neurol. 2006; 63:122-128. [PubMed: 16401744]

Van Buggenhout GJ, Descheemaeker MJ, Thiry P, Trommelen JC, Hamel BC, Fryns JP. Angelman syndrome in three adult patients with atypical presentation and severe neurological complications. Genet Couns. 2000; 11:363-373. [PubMed: 11140414]

Van Buggenhout G, Fryns JP. Angelman syndrome (AS, MIM 105830). Eur J Hum Genet. 2009; 17:1367-1373. [PubMed: 19455185]

Viani F, Romeo A, Viri M, Mastrangelo M, Lalatta F, Selicorni A, Gobbi G, Lanzi G, Bettio D, Briscioli V, Segni MD, Parini R, Viani GF, Romeo A, Viri M, Mastrangelo M, Lalatta F, Selicorni A. Seizure and EEG patterns in Angelman's syndrome. J Child Neurol. 1995; 10:467-471. [PubMed: 8576558]

Waltz NC, Beebe D, Byars K. Sleep in individuals with Angelman syndrome: parent perceptions of patterns and problems. Am J Ment Retard. 2005; 110:243-252. [PubMed: 15941362]

Williams CA, Frias JL. The Angelman (“happy puppet”) syndrome. Am J Med Genet. 1982; 11:453460. [PubMed: 7091188]

Williams CA. Neurological aspects of the Angelman Syndrome. Brain Dev. 2005; 27:88-94. [PubMed: 15668046]

Williams CA, Driscoll DJ, Dagli AI. Clinical and genetic aspects of Angelman syndrome. Genet Med. 2010; 12:385-395. [PubMed: 20445456] 


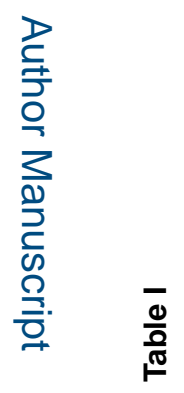

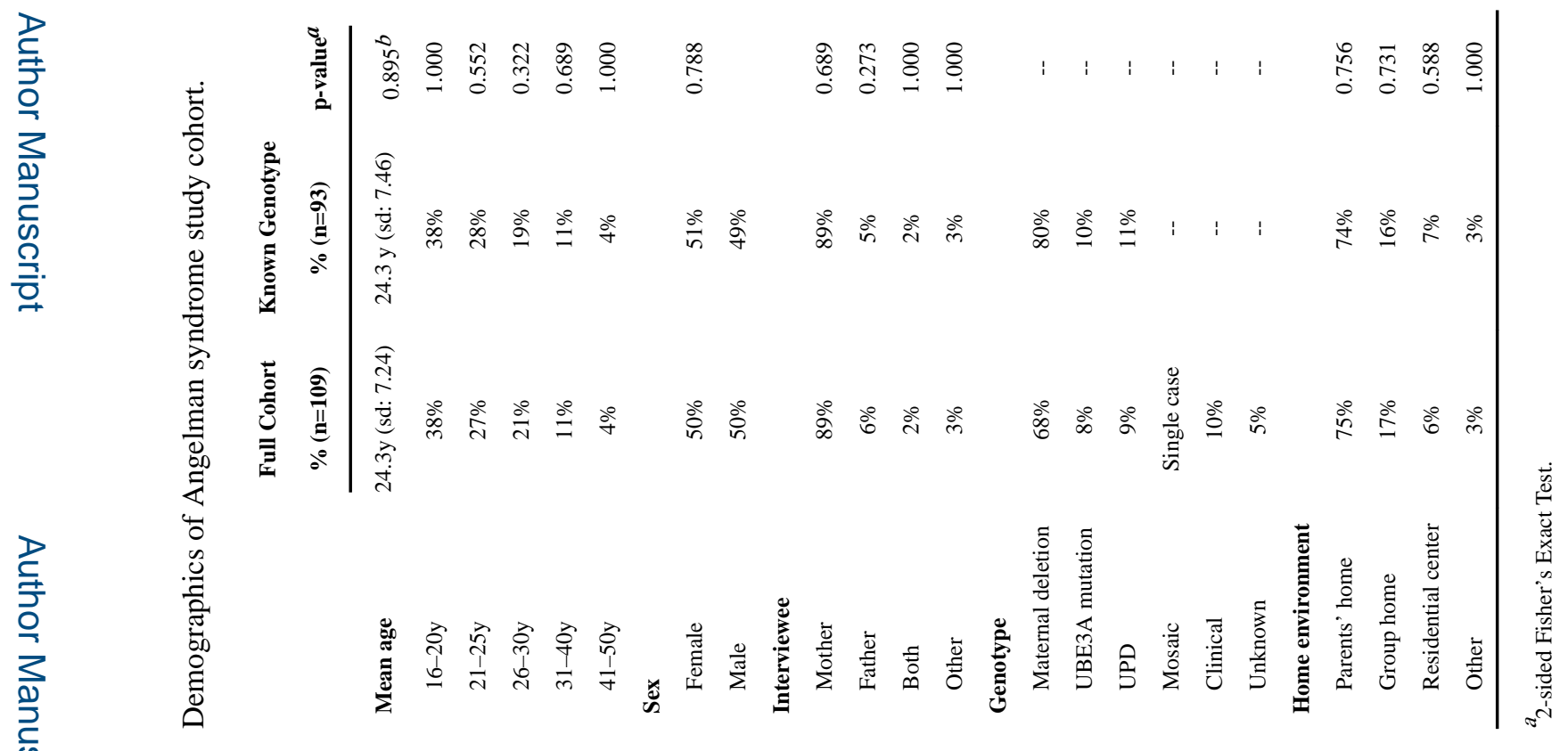
Am J Med Genet A. Author manuscript; available in PMC 2017 July 30. 


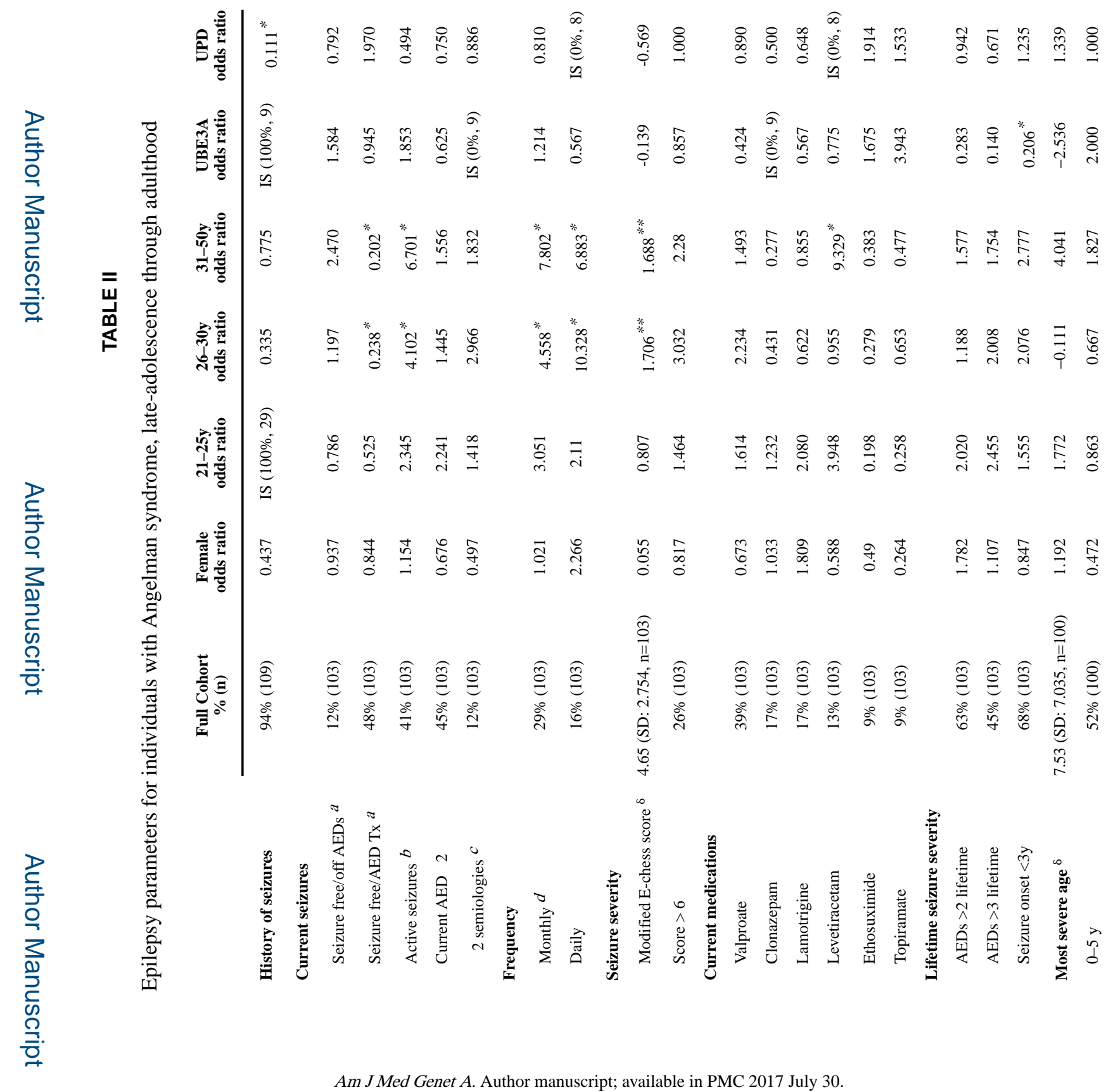




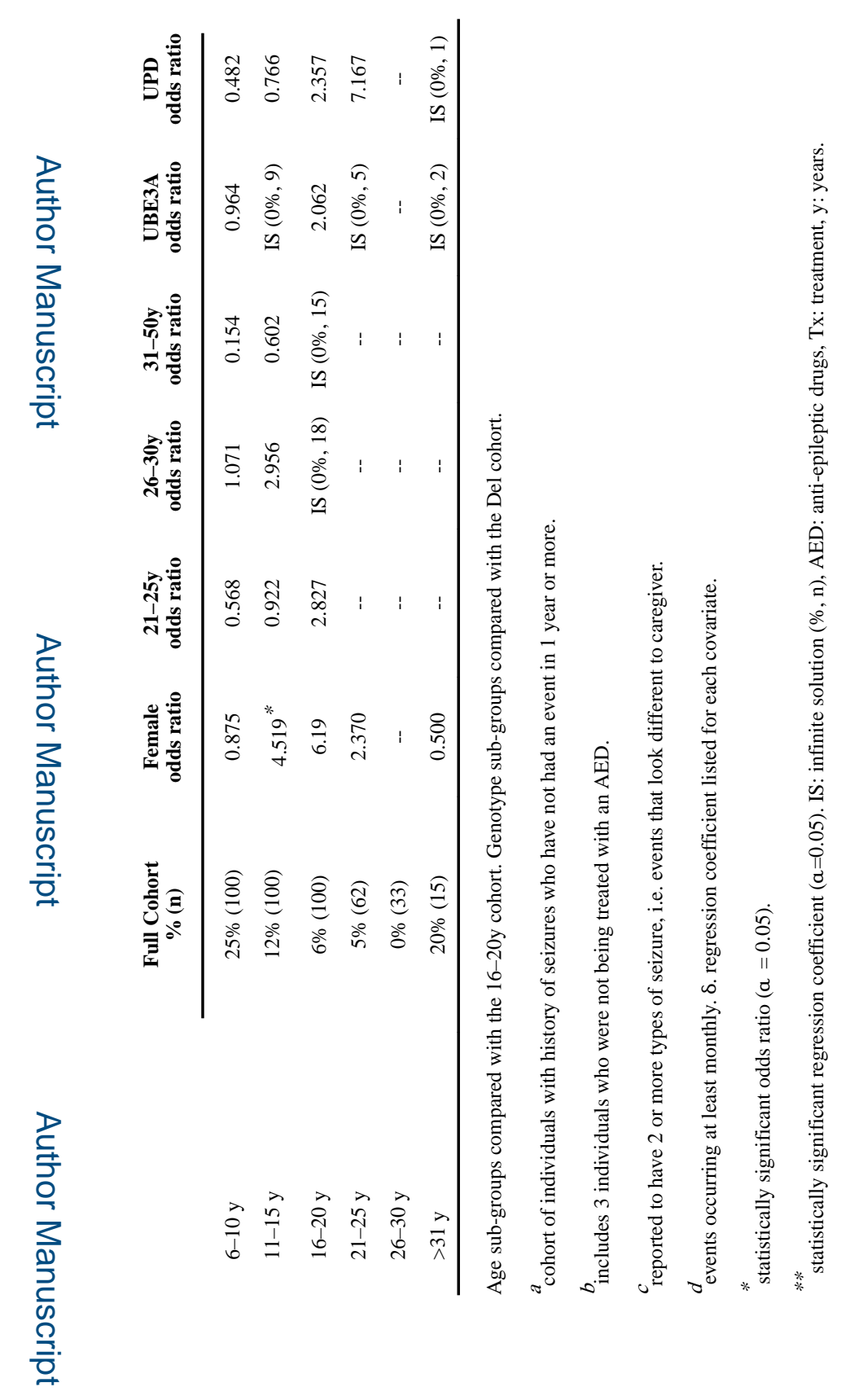

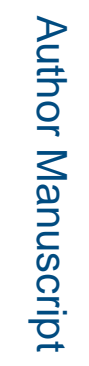




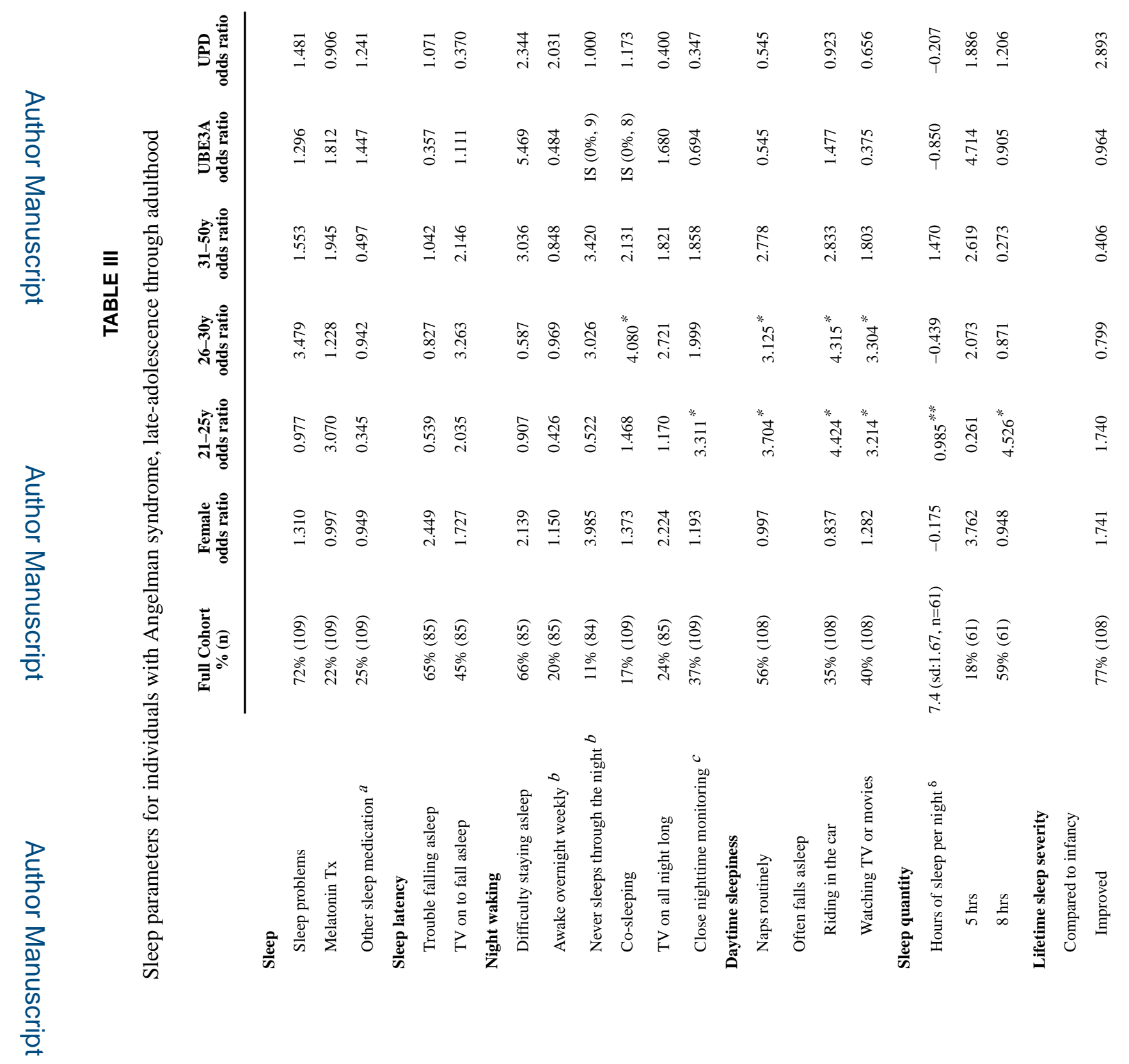
Am J Med Genet A. Author manuscript; available in PMC 2017 July 30. 


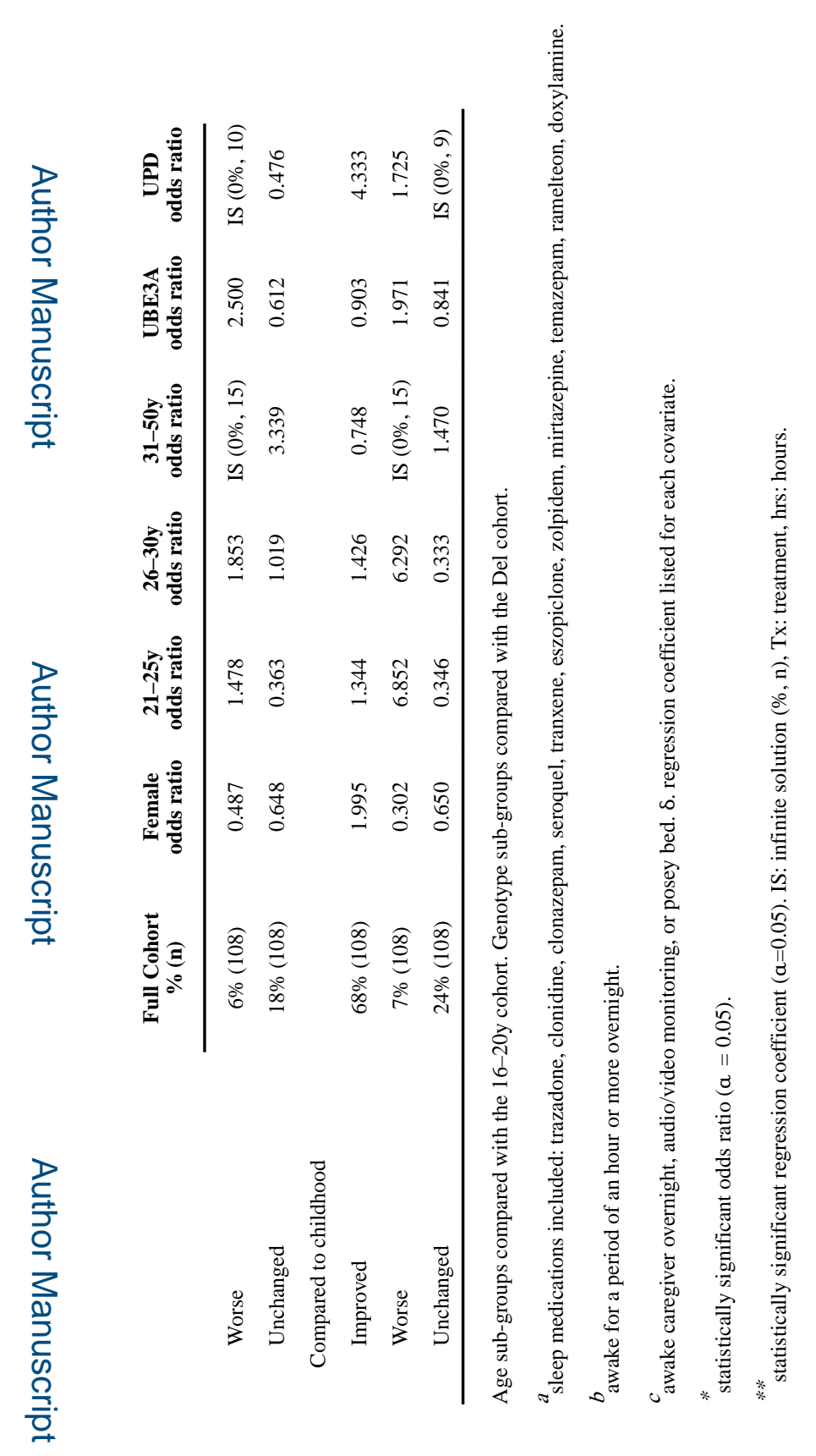

로을 


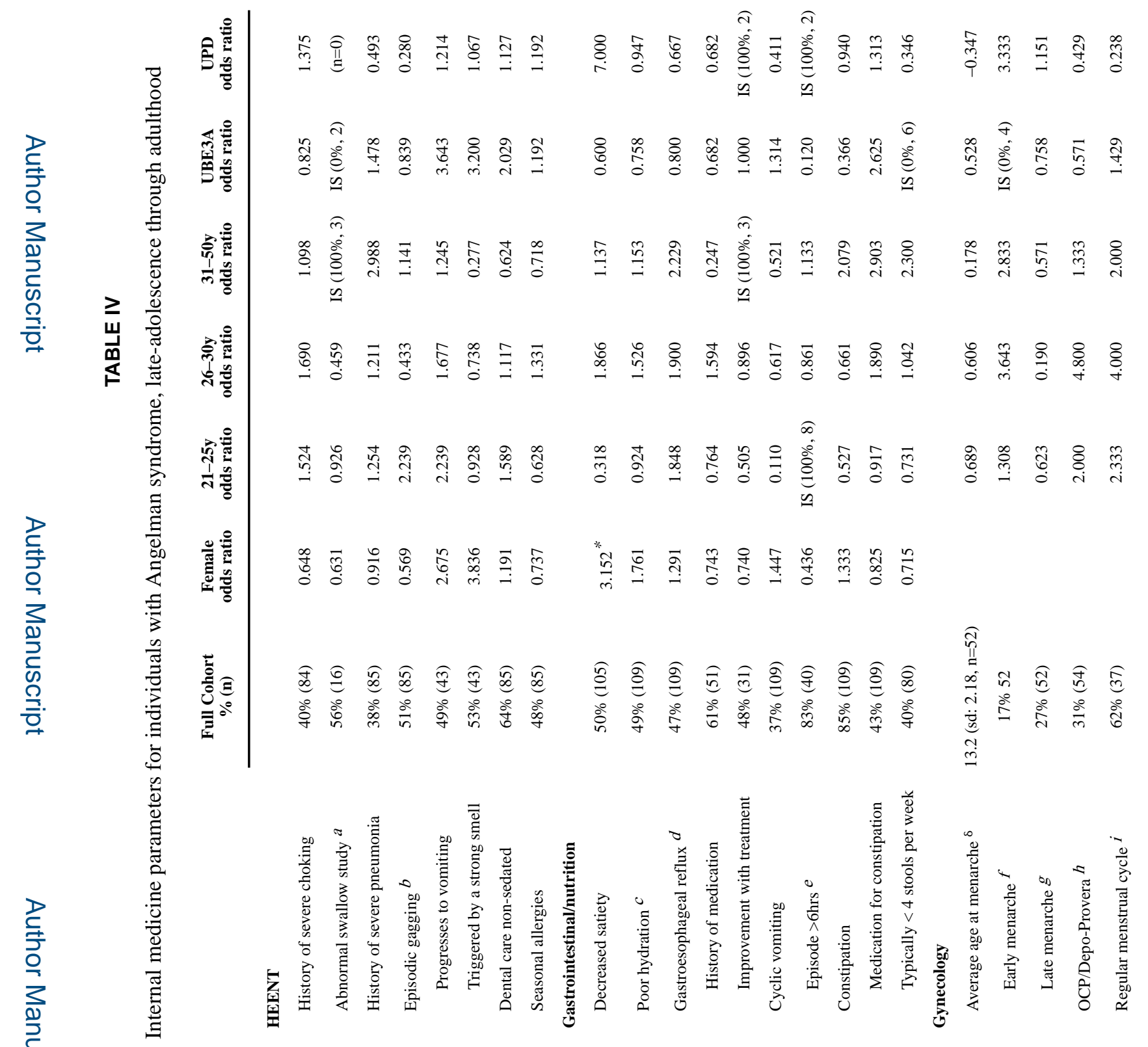




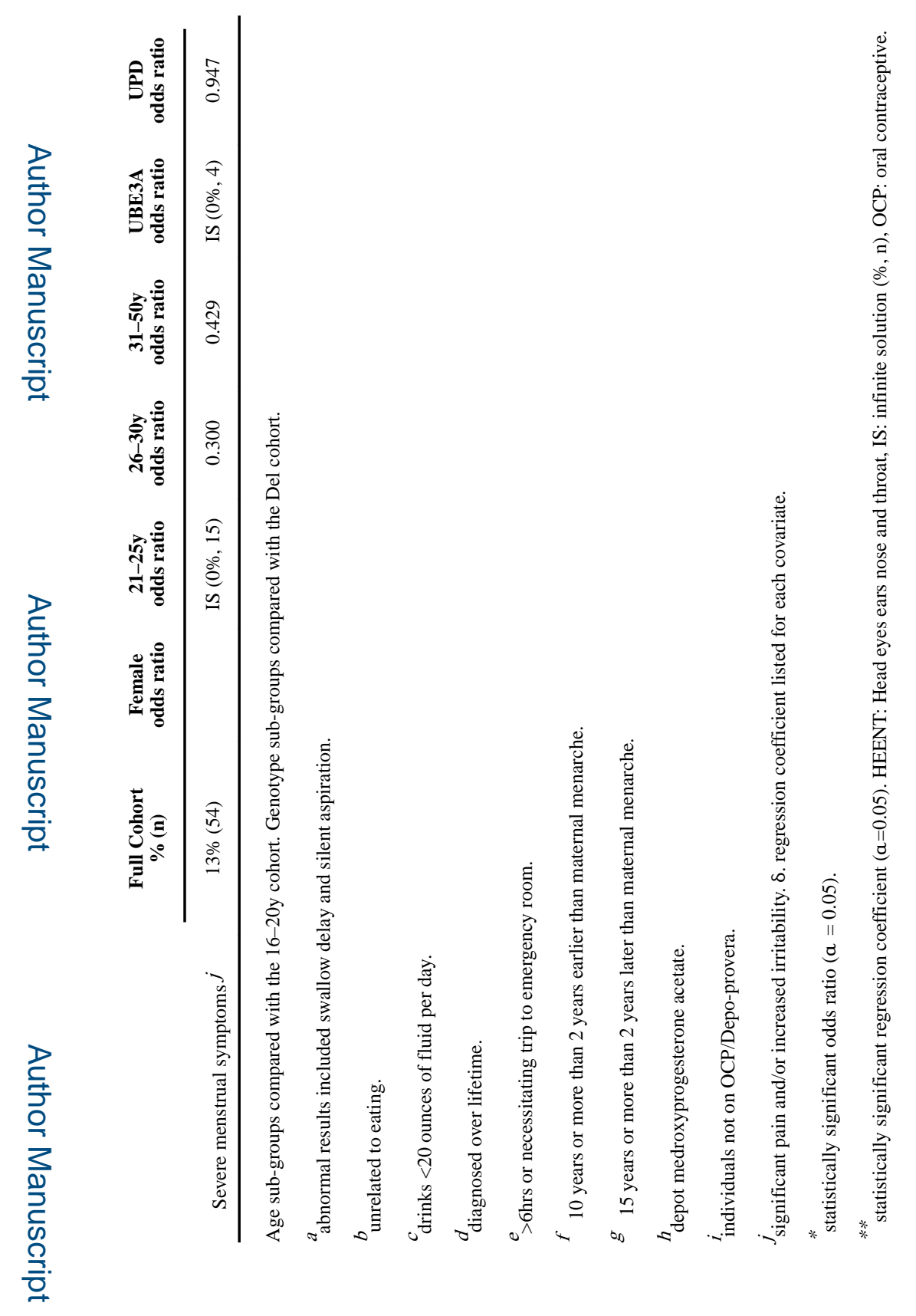

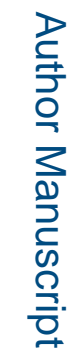




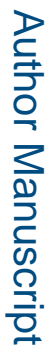

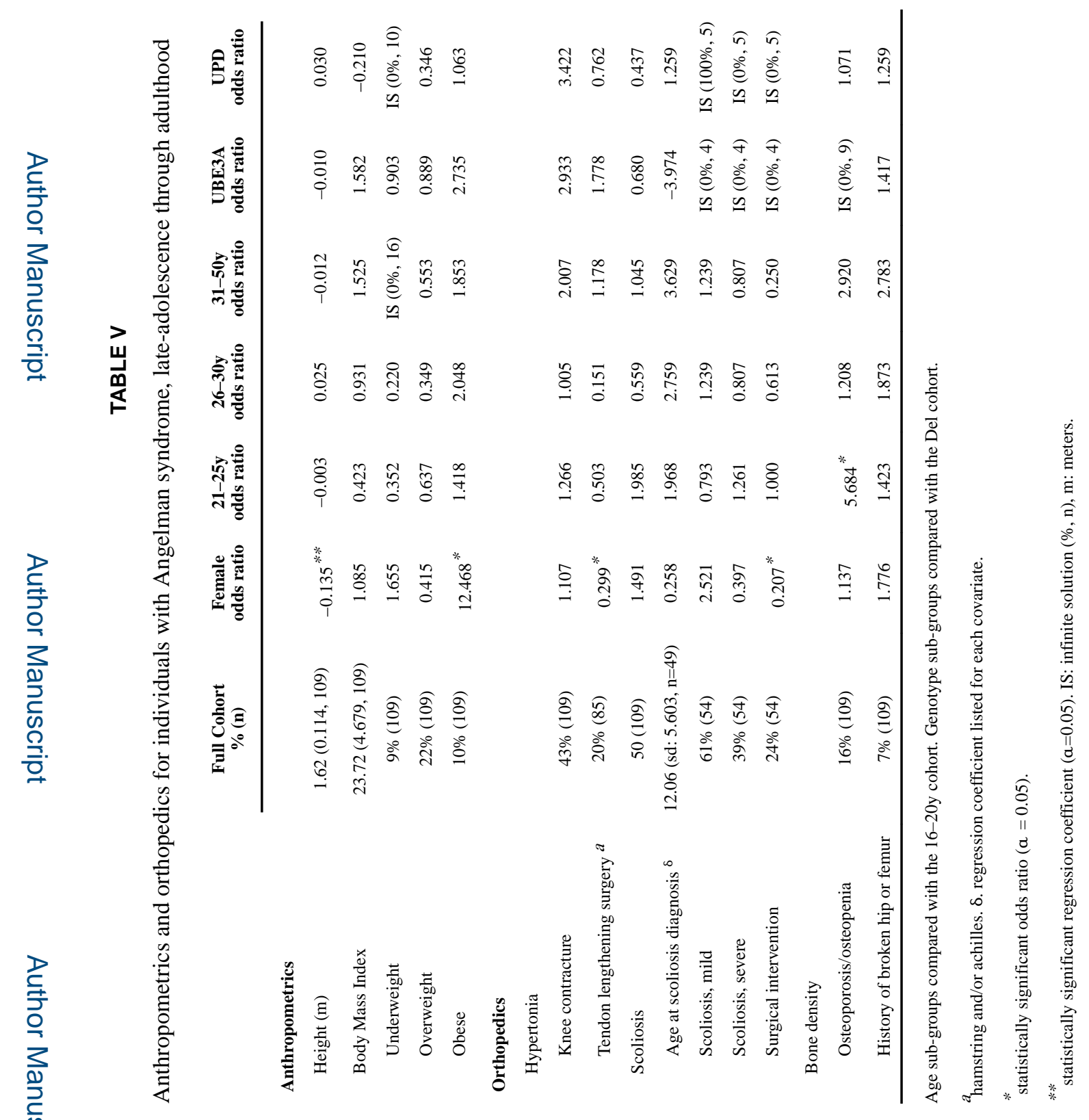




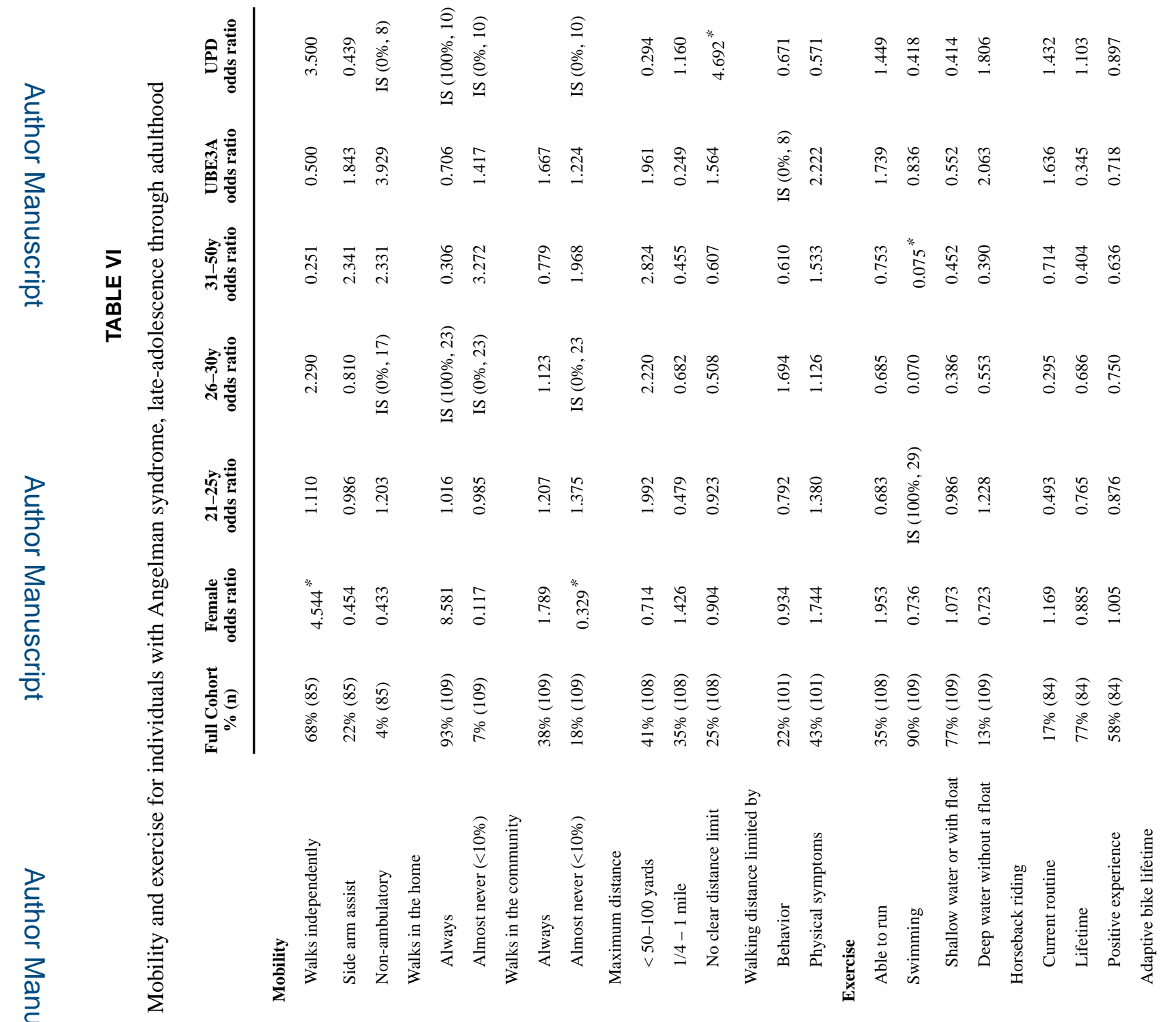




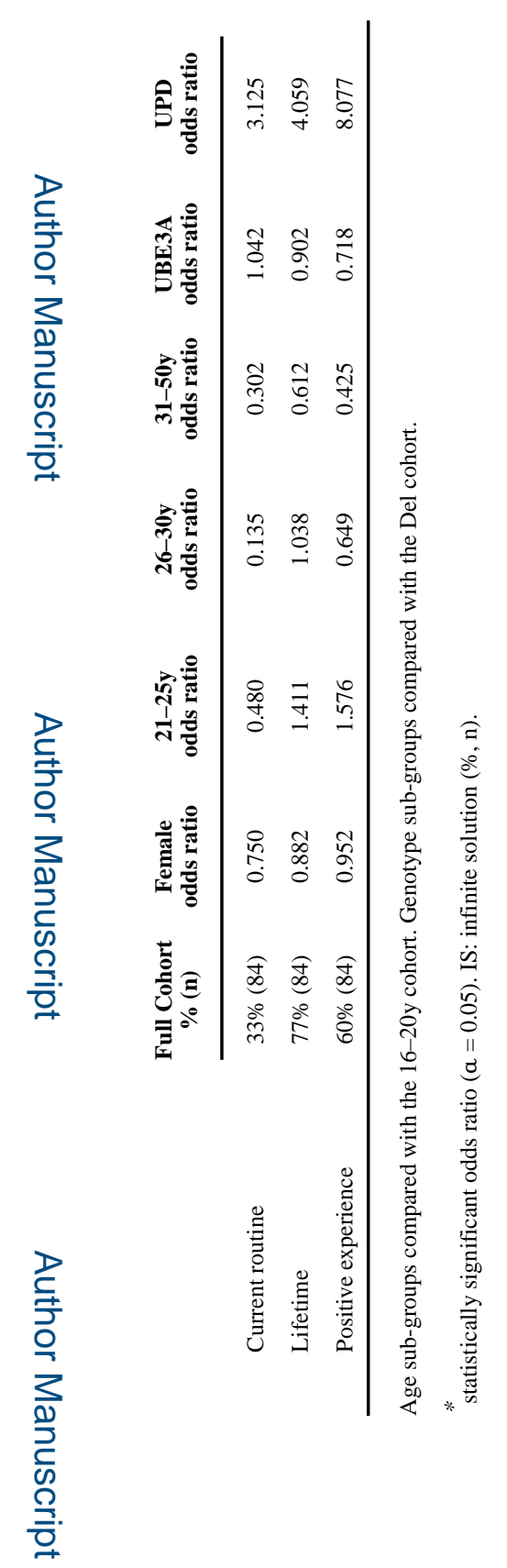

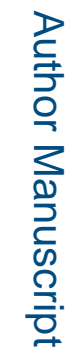




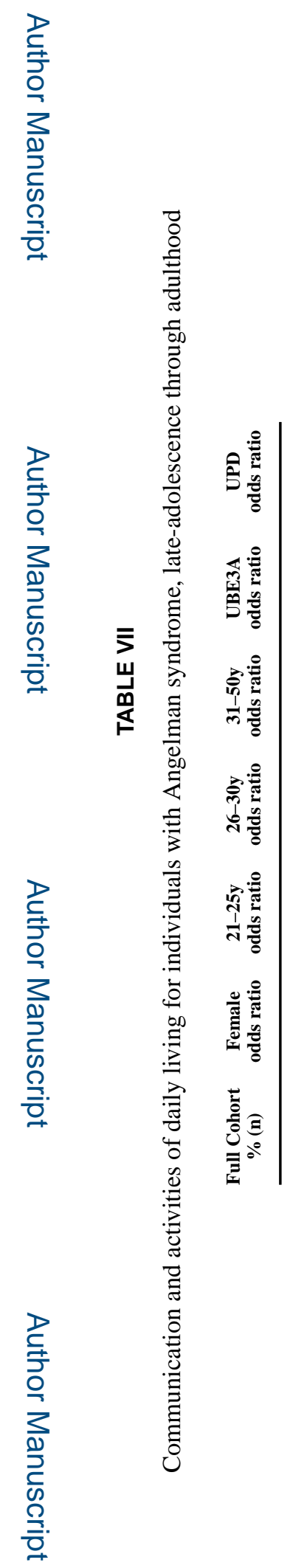

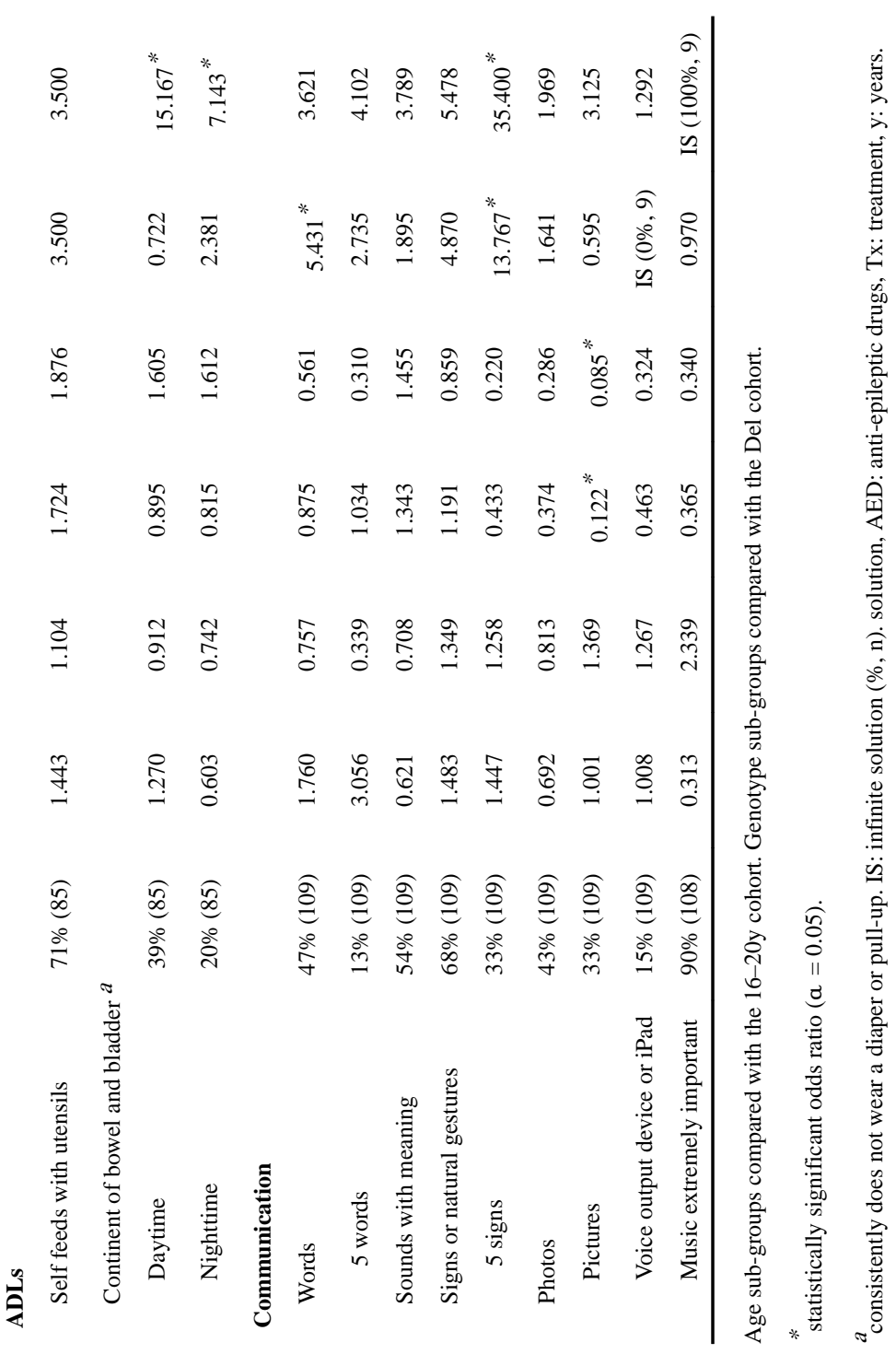




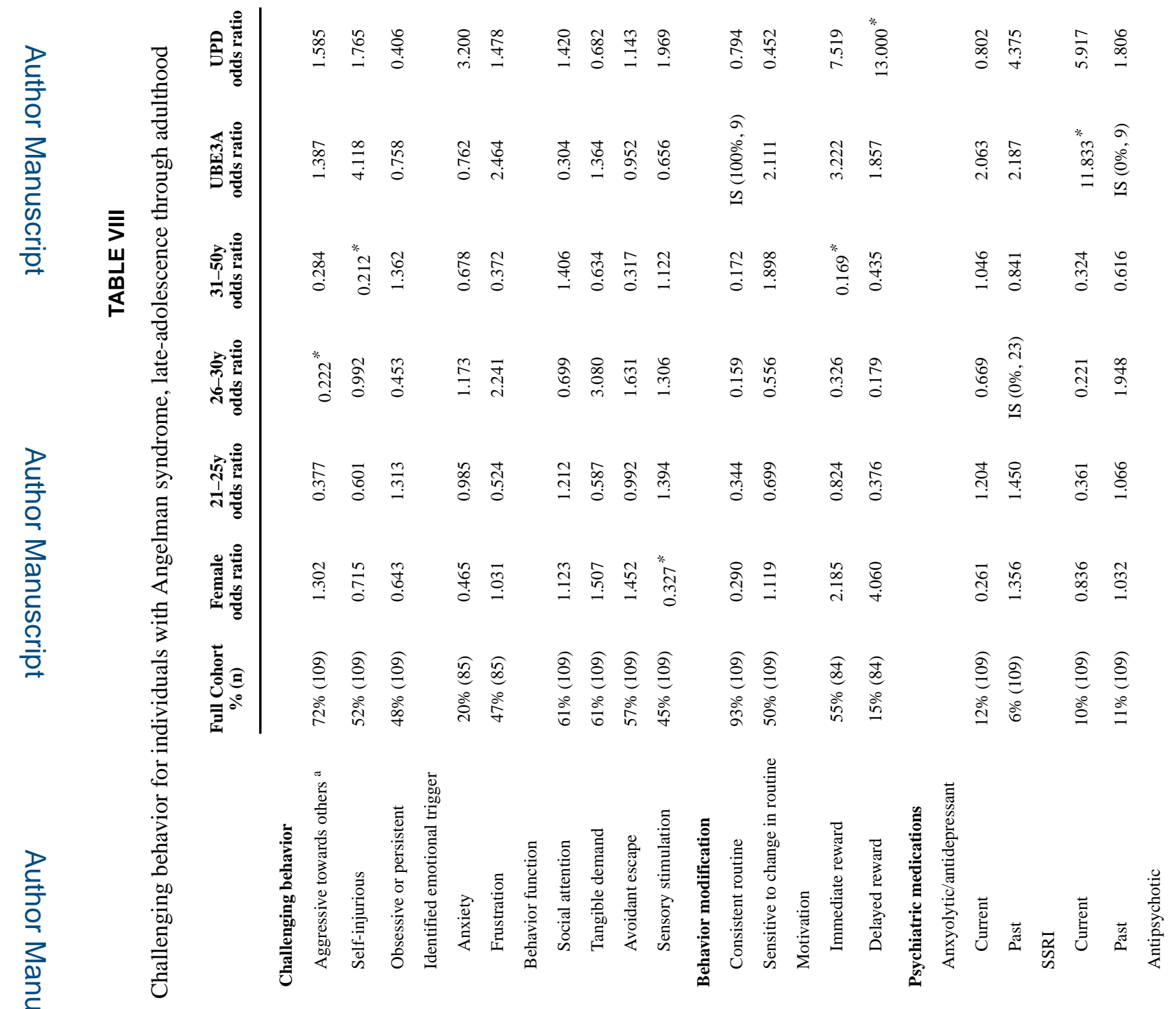

Am J Med Genet A. Author manuscript; available in PMC 2017 July 30. 


\section{롤}
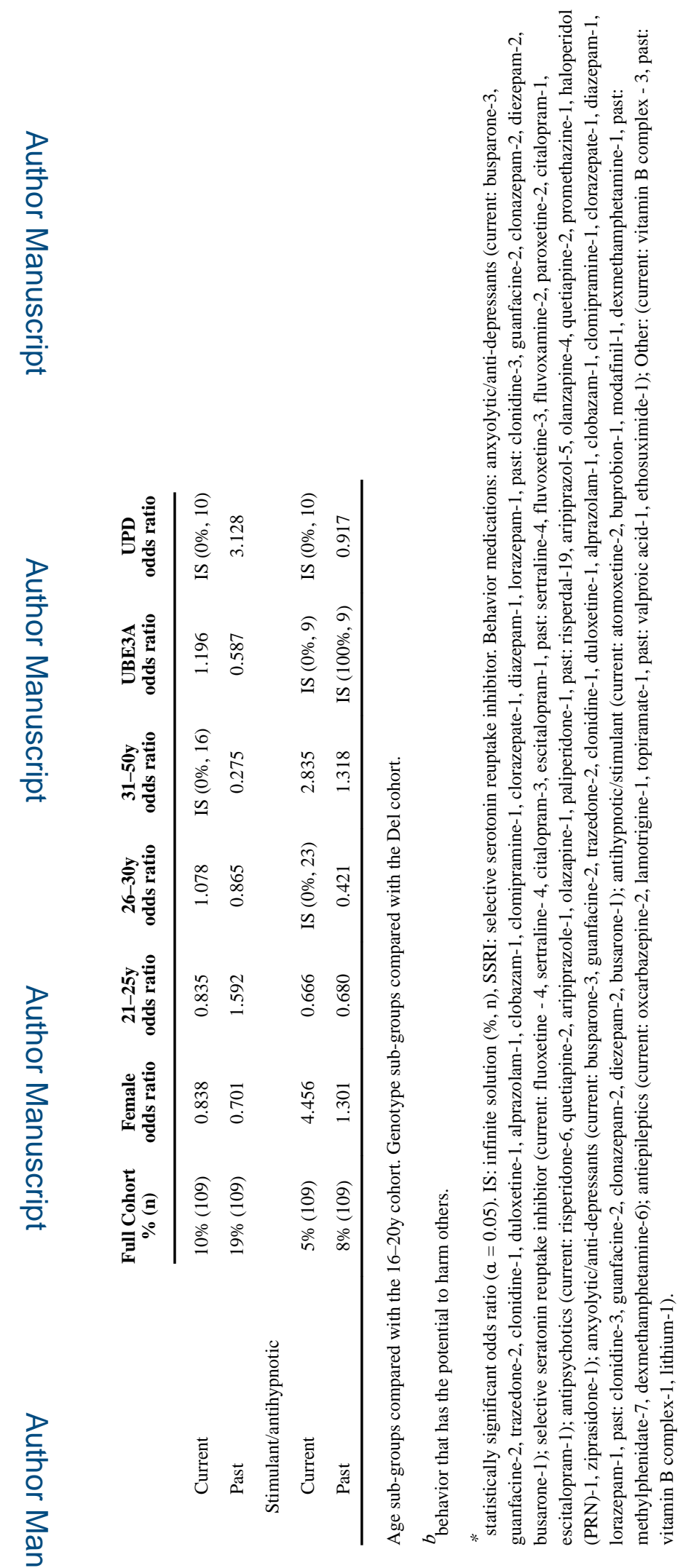